\title{
CINCO PROPOSICIONES SOBRE CERVANTES
}

\author{
Para Eulalio Ferrer Rodriguez
}

\section{La función Del Libro en DoN QuIJote}

En 1618 René Descartes abandona el estudio de las letras para aprender en "el gran libro del mundo". Don Quijote, contemporáneo casi exacto del filósofo, parto de un ingenio que ha llevado vida tan azarosa como la de Descartes, no aprende nada en el gran libro del mundo. Todo lo sabe de antemano, todo lo que sabe procede de su biblioteca. Recorriendo los caminos de la Mancha y de Aragón, el hidalgo cita, explica y glosa sus lecturas. En un primer momento predica esencialmente el evangelio caballeresco y en tono menor el evangelio pastoril: los Amadises y las Dianas nutren el discurso de Don Quijote en la Primera parte de la novela. El discurso del héroe se va diversificando en la Segunda parte, introduciéndose en él, al lado de los universos de ensueño que obsesionan al caballero, un amplio conjunto de problemas muy concretos que apasionan al hidalgo: la guerra, el duelo, la nobleza, el casamiento, las relaciones entre padres e hijos, los preceptos de la cortesía, las leyes de la ciudad ${ }^{1}$. En esta Segunda parte el discurso sobre la novela retrocede frente al discurso sobre las exigencias morales y la vida social. Estas reflexiones se alimentan de una cultura mucho más variada de lo que dejaría sospechar el inventario de la biblioteca del hidalgo, pero que evidencian sus

1 De puro sabido se nos olvida el hecho. Oportunamente nos recordó AL. BERTO SÁNCHEZ la importancia de las cuestiones políticas en la Segunda parte de la novela ("Arquitectura y dignidad moral de la Segunda parte del Quijote", ACerv, 18, 1979-80, 17-19). 
pláticas. En cuanto a las letras sagradas, el Evangelio, el Libro de Job, el Libro de los Proverbios, los Salmos. En cuanto a obras científicas, el Dioscórides del doctor Laguna y sin duda unas misceláneas eruditas de las que habrá sacado el hidalgo sus razonables conocimientos en materia de cosmografía, lingüística, historia y mitología. En el terreno de la ciencia política, la Parénesis de Isócrates, El perfecto regidor (1586) de Juan de Castillo y Aguayo, acaso la Política para corregidores (1597) de Jerónimo Castillo de la Bobadilla y alguna obra más ${ }^{2}$. Por lo que toca a la literatura didáctica, unas colecciones de fábulas (Esopo, Fedro), un tratado de poética por lo menos (verosímilmente el de Alonso López Pinciano) y un tratado de urbanidad, el Galateo español de Lucas Gracián Dantisco. En cuanto a poesía, los versos de Garcilaso y quizás la Eneida, aunque las frases en que remite Alonso Quijano al poema virgiliano pueden proceder de una miscelánea erudita. Alonso Quijano se nos aparece como un hidalgo excepcionalmente culto: muy dudoso resulta que la generalidad de los hidalgos del Siglo de Oro manifestaran tan decidida inclinación a la lectura. Detalle elocuente: la novela sólo en una ocasión apunta las aficiones cinegéticas de Alonso Quijano $(1,1)$ cuando la caza fue una de las actividades a que más asiduamente se dieron los hidalgos del siglo. Alonso Quijano es el hombre del libro.

A tan apreciable cultura corresponden un lenguaje exquisito y un vocabulario castigado. Recomienda el hidalgo que se apele al eufemismo (II, 43), en lo cual coincide una vez más con el libro, y más concretamente con un libro, el Galateo español (pp. 108 y 167$)^{3}$. Además Alonso Quijano no entiende la jerga de los galeotes $(I, 22)$. Sorprende tal ignorancia en hombre de tanta lectura. Hasta si nos negamos a aceptar la hipótesis (muy verosímil) según la cual los Romances de germanía reunidos por Juan Hidalgo se habrían publicado en fecha anterior a 1609 , convendrá reconocer que no escaseaban las colecciones en que se podían leer las obritas de este género: el Cancionero general (a partir de 1557), la Rosa de amores (1573) de Juan Timoneda, el Romancero (1583) de Pedro de Padilla - y eso sin contar con miles y miles de pliegos. Verdad que en 1605 Quevedo todavía no ha compuesto sus ma-

${ }^{2}$ Sobre las fuentes del pensamiento político de Alonso Quijano véanse en especial AmÉrico CASTRo, El pensamiento de Cervantes, Noguer, Barcelona, 1972, pp. 353-355, y las notas de Schevill-Bonilla y Rodríguez Marín a los caps. 42 y 43 de la Segunda parte del Quijote.

${ }^{3}$ Remito a la edición del Galateo que debemos a Margherita Morrea. LE, CSIC, Madrid, 1968. 
ravillosas jácaras. Con todo ... De aquel vocabulario que se ha deslizado en las imitaciones de La Celestina desde 1521, que Cervantes maneja con tanta soltura, que entra en el teatro de Lope hacia 1602, ¿no sabría nada Alonso Quijano? La hipótesis es insostenible. La única solución razonable de este misterio consiste en admitir que el novelista quiso conscientemente que su honesto hidalgo desconociera la jerga de los rufianes.

Germanía aparte, Alonso Quijano se expresa con refinada elegancia. Emplea con discreción y parsimonia los modismos petrificados que Francisco de Quevedo acaba de calificar de "bordoncillos inútiles"': los refranes, como es sabido; los versos de romances, también. Cierto que Don Quijote gusta de evocar las bellas historias de amor y muerte que flerecen en el Romancero. Pero los versos de romances que han venido a ser muletillas de la conversación, éstos no los emplea Alonso Quijano, los abandona a Sancho Panza. ¿Y qué diremos de los cuenteerhos? Como cualquier contemporáneo suyo Alonso Quijano conoce y refiere cuentecillos. Pero dosifica su empleo homeopáticamente: no es él hombre para lanzarse a una de estas justas de mentiras que gustosos practican en aquel entonces caballeros españoles y caballeros franceses ${ }^{4}$. Además son cuentecillos referidos con brevedad, en los que el narrador cuidadosamente ahorra los detalles superfluos y se guarda de perderse en un laberinto de circunloquios aburridos. Alonso Quijano respeta los preceptos del Galateo 5 .

Por fin el arte de la conversación refinada tal como lo practica Alonso Quijano excluye las figuras de la agudeza verbal que Cervantes considera evidentemente como vulgares e indignas de un discreto. He procurado demostrar en otra ocasión que el apodo y el equívoco son las figuras fundamentales de los juegos de ingenio cortesanos a lo largo del siglo xvi y en las primeras décadas del siglo siguiente ${ }^{6}$. Estas figuras, según documentan los viajeros

"Sobre este punto véase mi artículo "Cuentos de mentiras", Studia in honoren Prof. M. de Riquer, Quaderns Crema, Barcelona, 1986, t. 1, pp. 289-298.

${ }^{5} \mathrm{Y}$ Sancho no. Véase en particular el cuento malicioso que refiere el escudero para ilustrar las reglas que rigen la jerarquía de los asientos a la mesa (II, 31). El cuento es sencillo: podría, y debería, relatarse brevemente. Pero Sancho lo rellena con tantas digresiones que resulta embrollado e interminable. El relato quebranta en forma tan sistemática los preceptos del Galateo que no parece dudoso que Cervantes, al escribir este capítulo de la novela, recordara el texto de Gracián Dantisco y gustara de dar muestra del estilo de que ha de huir cualquier narrador.

6 "El arte de motejar en la corte de Carlos V", CuLH, 5 (1983), 61-77; 
extranjeros, se practican abundante y agudamente en la España de Cervantes. Estas figuras propone Cervantes que se proscriban. “Apode el truhán”, pronuncia Berganza7. Alonso Quijano, por su parte, no cultiva el apodo. Con una excepción: apoda al Barbero (II, 1), indicio evidente de que el cuentecillo picante de éste le ha herido en lo más vivo. En cambio no apoda nunca a Sancho, cuya morfología lo predispone a ser blanco privilegiado para tales flechas. "Los gordos -escribe Luis Zapata- se hacen terrero de graciosos y fisgantes, y son molde de dichos, de motes y de apodaduras' 8 . En cuanto al equívoco no lo maneja nunca Alonso Quijano, si he leído correctamente el libro. Lo reserva el novelista para la Ventera (I, 32), para Tomé Cecial (II, 13) y para el mayordomo que hace el papel de la Trifaldi (II, 40). Y para el duque. Cuando pretende Sancho haber jugado con las cabrillas celestes, salta el duque: "Decidme, Sancho: ¿vistes allá entre estas cabras algún cabrón?" (II, 41). No lo dudemos, estas razones le imprimen al personaje un sello negativo. Pero quédese este aspecto para otro lugar. Lo que importa por ahora es que el duque se expresa como un caballero de su época. Y. Alonso Quijano, no. Alonso Quijano obedece a los preceptos de los tratados de urbanidad, Alonso Quijano obedece a los preceptos del libro.

La cortesía y los buenos modales para concluir. Gusta Don Quijote de proclamar que adquirió la virtud de la cortesía el día en que abrazó el oficio de caballero andante (I, 50). Afirmación ésta que no hemos de aceptar sin examen. Puede que nos acerquemos más a la verdad defendiendo el parecer exactamente opuesto, dado que es el andante mucho más que el hidalgo quien trata mal de palabra al cabrero (I, 52) y a Diego de Miranda (II, 17). Cualquiera que sea nuestra convicción sobre el particular, es indudablemente Alonso Quijano quien demuestra perfecta urbanidad y elegante soltura frente a un gran señor como don Fernando y más tarde cuando le reciben en el palacio ducal. Es indudablemente Alonso Quijano quien aparece allí como "escuela de la mis-

"Le gentilhomme et le galant. À propos de Quevedo et de Lope", BHi, 88 (1986), 5-46.

7 Novelas ejemplares, en Obras completas de Miguel de Cervantes SaAvedra, eds. Schevill-Bonilla, B. Rodríguez, Madrid, 1914-1941, t. 3, p. 173. Obsérvese que en los mismos años en que escribe Cervantes esta frase florece el apodo en las calles de Valladolid, según demuestra la Fastiginia de Pinheiro da Veiga.

${ }^{8}$ Luis Zapata, Miscelánea, núm. 47, Clásicos Castilla, t. 1, p. 127. 
ma cortesía", de buenos modales, según ha de observar la propia duquesa (II, 32).

Esta cortesía refinada ¿dónde la habrá aprendido Alonso Quijano? No será en la compañía del cura y el barbero de su pueblo. A esta pregunta conviene una sola respuesta: esta cortesía el hidalgo la habrá aprendido en los libros. Y no en los libros de caballerías que son "en las cortesías mal mirados" (I, 47). La aprendió en un tratado de urbanidad: el Galateo español. Sobre los preceptos del Galateo amolda su conducta, demuestra en particular su actitud cuando el duque le manda que tome la cabecera de la mesa (II, 31; Galateo, p. 137).

$\mathrm{Y}$ en los preceptos del Galateo se inspiran con frecuencia los consejos que da Alonso Quijano al gobernador de Barataria: conviene vestir según su estado (II, 51; Galateo, pp. 113, 117, 180); el vestido no ha de ir desceñido (II, 43; Galateo, p. 180); conviene caminar despacio (II, 43; Galateo, pp. 180-181); conviene comer y beber templadamente (II, 43; Galateo, p. 179); conviene hablar con reposo (II, 43; Galateo, p. 113).

Cierto que no supone ninguna originalidad el observar la huella que dejó el Galateo en la novela cervantina: hace tiempo que la apuntaron los eruditos. Pero no se ha valorado esta influencia como lo merece. Hemos preferido evocar a propósito de Don Quijote el Cortesano de Castiglione cuya estampa en la novela es indecisa y finalmente impalpable. Se entiende este esfuerzo erudito porque el tratado de Castiglione se sitúa muy por encima del Galateo, puro manual de cortesía, y es incomparablemente más rico y bello que él. Pero se trata de un esfuerzo desesperado. Entre los tratados de la vida palaciega y de la urbanidad es indudablemente el libro de Giovanni Della Casa, no el del conde Castiglione, el que imprime su sello en el Quijote. ¿Habremos de lamentar el hecho? De reaccionar así, desconoceríamos la importancia que cantidad de buenos ingenios del Siglo de Oro conceden al aseo del vestido, al comer limpiamente, a la corrección y la pureza del lenguaje, a la honestidad de los vocablos, al cuidado que se ha de poner en evitar mencionar unas realidades nauseabundas o desagradables, en una palabra, a los buenos modales. Este código de buena educación parecerá convencional y mezquino a nuestros contemporáneos. Pero ¿acaso no tendrían nuestros antepasados sus motivos para opinar como lo hacían? Los preceptos de la cortesía eran para ellos la manifestación tangible de un control de la afectividad y las pulsiones; eran para ellos, en el siglo violento en que vivían, la condición de una vida en común relativamente 
pacífica y armoniosa dentro de lo posible ${ }^{9}$. Para estos efectos el Galeteo bien valía el Cortesano. Menos ocupado en teorizar y filosofar, enunciaba cien menudas prescripciones cuya observancia prometía a los humanos una vida más sosegada. La historia había de ratificar esta opción: el Galateo servirá de manual de educación durante dos siglos mientras que el Cortesano se hunde en el olvido.

Don Quijote es el hombre del libro, Alonso Quijano también ${ }^{10}$. En las páginas de la novela cervantina se va dibujando lentamente una doble cultura: la una, que ocupa preferente lugar en las charlas de la Primera parte, es puro entretenimiento; la otra, que impera en las pláticas de la Segunda parte, es ilustración y consuelo ${ }^{11}$. Leyendo libros enloqueció el hidalgo, y este carácter de alucinación es el que ha seducido a la crítica contemporánea, como la de Marthe Robert, Michel Foucault y algunos más. Pero no menos cierto resulta que los libros han alimentado las meditaciones de Alonso Quijano y que al calor de los libros brotó aquella cortesía exquisita que admiran tantos personajes de la novela, y sobre todo aquella sabiduría generosa que maravilla a Sancho Panza. El libro ejerce doble función dentro de la novela, y el poder maléfico de las novelas caballerescas tiene su contrapeso en los libros a cuyo contacto ha venido a ser Alonso Quijano dechado de hidalgos.

\section{Don Quijote y Alonso Quijano}

Alonso Quijano demuestra interés por los conocimientos científicos, afición a las buenas letras, apego a los preceptos de la urbanidad y al decoro. Su cultura mantiene sutil equilibrio entre los valores profanos y los valores devotos. Llevados de la desmedida

${ }^{9}$ Phillippe Ariès, L'enfant et la vie familiale sous l'Ancien Régime, Éds. du Seuil, Paris, 1973, p. 277.

${ }^{10}$ Y Cervantes el hombre de la imprenta. Cuando defendí la idea en un coloquio sobre hidalgo e hidalguía (Burdeos, octubre de 1987), me parecía original la afirmación. Luego me enteré de que otro cervantista, Eulalio FERRER RoDRíGuez, había destacado ya el interés del novelista por la imprenta (véase "Comunicación en la comunicación", El Quijote y la comunicación, Ediciones de Comunicación, México, 1983, esp. p. 84). Por eso le dedico, con admiración y afecto, el presente estudio.

11 "'La invención de Cervantes es conforme al carácter de un hidalgo de harto buen juicio que, aviéndole ilustrado con la letura de los libros, le perdió desvelándose en los de cavallerías [...]"' (G. MaYans, Vida de Miguel de Cervantes Saavedra, Espasa-Calpe, Madrid, 1972, p. 37). 
atención que hemos concedido a unas interrogaciones sobre el cristianismo del andante $-\mathrm{y}$ el de otros personajes de la novela ${ }^{12}$-, casi estamos por olvidarnos de tan exquisito equilibrio. En lo cual andamos descaminados porque este equilibrio es justamente la clave de esta arquitectura cultural, y nos tendría que impresionar por ser el mismo que había de brillar pocos años más tarde en el honnête homme francés. Paul Hazard esbozó un paralelismo entre Don Quijote y el honnête homme ${ }^{13}$. Antes que él el siglo xvII ya había advertido el hecho: Don Quijote, escribe Pierre Perrault, es "très honnête homme"14 - a falta de traducción exacta propongamos una equivalencia y digamos que Don Quijote es un discreto-, observación atinada si las hay.

Pero observación que suscita un reparo: más vale corregir la frase de Perrault sustituyendo a Don Quijote por Alonso Quijano. Posiblemente vislumbrara Perrault que el discreto no era Don Quijote, sino Alonso Quijano. Pero su declarado aristotelismo lo encandiló y no le permitió percibir claramente la verdad que estuvo a punto de descubrir, a saber, que por la novela cervantina van circulando dos personajes distintos que llevan con frecuencia el mismo nombre de Don Quijote. Porque a la doble cultura que he procurado definir corresponde un personaje doble. Cervantes lanza a la novela dos personajes: Don Quijote el loco y Alonso Quijano el cuerdo. No sólo en el primer capítulo de la Primera parte y en el último de la Segunda parte interviene Alonso Quijano, sino en otros muchos capítulos del libro. Cuando la primera salida del héroe quien habla y actúa es Don Quijote. En la segunda salida predomina Don Quijote, aunque asoma Alonso Quijano. En la tercera salida prevalece Alonso Quijano frente a un Don Quijote que se va esfumando. O con otras palabras, apelando al vocabulario de la pintura barroca, la Primera parte de la novela

12 Tiene razón EdWard C. RILEY cuando opina que "indudablemente el problema de las opiniones religiosas y morales de Cervantes ha sido inflado por los críticos, a partir de 1920, hasta más allá de sus límites reales" (Teoría de la novela en Cervantes, Taurus, Madrid, 1966, p. 157). Este desequilibrio de nuestros estudios nos oculta unas evidencias: en especial la decencia del vocabulario cervantino se suele achacar a la Contrarreforma cuando se ha de atribuir a un decoro que es concepto puramente laico. Punto es éste sobre el cual volveré en otra ocasión.

13 "Don Quichotte" de Cervantes, étude et analyse, Mellottée, Paris, 1949, p. 240 .

${ }^{14}$ Critique du livre de Don Quichotte de la Mancha (1679), ed. Maurice Bardon, Champion, Paris, 1930, p. 237. 
es el Triunfo de Don Quijote, la Segunda parte la Apoteosis de Alonso Quijano. Por un juego de manos digno de un prestidigitador Cervantes ha sustituido un personaje por otro. Desde este enfoque resulta fácil definir el Quijote de Avellaneda: es novela en la que Alonso Quijano no aparece nunca.

Alonso Quijano suscitó un entusiasmo muy relativo. El siglo XviI, encariñado con la parodia, prefirió a Don Quijote; el siglo XIX, seducido por la locura y encaprichado con los héroes que se sienten incómodos en la ciudad de los hombres, únicamente conoció al andante y se olvidó del hidalgo ${ }^{15}$. Nuestro siglo parece mantener la misma exclusiva. Porque sigue repitiendo el paralelismo entre Don Quijote e Illusions perdues. Ahora bien, paralelismo es éste que no se puede defender, porque bifurcan los senderos de las dos novelas. Cuando encarcelan a Lucien de Rubempré, se hunde el personaje, que es todo fachada. Cuando es derribado Don Quijote, queda en pie Alonso Quijano; cuando es derrotado el andante, sigue ileso el discreto. Don Quijote será novela del fracaso - hasta cierto punto-, pero en ningún caso de la desesperación. Porque si se deshacen las quimeras del caballero, siguen vigentes los valores que defiende el hidalgo. Tenemos derecho a considerar estos valores como trasnochados, y podemos leer el libro como se nos antoje. En cambio, si lo queremos estudiar, será prudente evitar el doble contrasentido en que cayeron ( $y$ caen) los románticos y sus herederos espirituales: el texto no sugiere que la locura sea vía de acceso privilegiada al saber ni que Alonso Quijano viva en disconformidad con la sociedad de su tiempo.

\section{Sancho Panza y su amo}

Frente a Don Quijote, ebrio de novela, frente a Alonso Quijano, nutrido de buenas letras, representa Sancho, Sancho el analfabeto, Sancho el de los refranes, el mundo de la oralidad. La novela y sus exégetas tan constantemente nos sugieren esta imagen que atrevida parecerá cualquier tentativa de cuestionarla. Sin embargo no parece descaminada la idea de matizar representación tan comúnmente recibida. No faltan en efecto en la historia de Don Quijote y Sancho las charlas y acciones en que demuestra el escu-

${ }^{15}$ Recuérdese que Herder reputaba ilegible la Segunda parte del Quijote y que el propio Goethe no gustaba de ella (J. J. A. Bertrand, Cervantès et le romantisme allemand, Alean, Paris, 1914, pp. 73 y 520). 
dero poseer conocimientos de fuente erudita. En especial las sentencias sanchopancescas, que tan frecuentemente quisieron los comentaristas de la novela achacar al buen sentido característico del campesino y acercar a unos paradigmas "populares", muy poco tienen de tradicional. Posiblemente pertenezca a la tradición oral la historia del sastre y las caperuzas, aunque el hecho no resulta de los más evidentes. Pero son puramente eruditos los pleitos del báculo de los escudos, de la mujer supuestamente violada y de la carrera del gordo y del flaco. Quiso Cervantes que brillara la agudeza de Sancho en unas sentencias de tradición escrita, en unos pleitos que mal podía conocer un analfabeto. Quiso que Sancho participara en cierta medida de la cultura que da o confirma el libro, quiso que al campesino iletrado le tocara un destello de la gracia que dispensa la cultura libresca ${ }^{16}$. Desemboca esta conducta del novelista en unos episodios que podemos legítimamente tachar de inverosímiles. Tal inverosimilitud tendrá su explicación, y nos toca aclarar sus motivos. Pero conviene ante todo advertir el fenómeno.

Declara Sancho haber aprovechado las enseñanzas de su $\mathrm{amo}^{17}$. Pero ¿de cuál de los dos?, ¿de Don Quijote? Imposible. Sancho no comprende al andante, tampoco comprende la literatura de los Amadises. De caballerías únicamente entiende lo que es preciso para engañar a su señor. Pero no admira "la ciencia andantesca". Sí admira en cambio la generosidad, la sabiduría y la humanidad de Alonso Quijano, una generosidad que sabe apreciar el escudero, una sabiduría que puede entender el campesino, una humanidad que ha de recordar el gobernador de Baratarla. Ruego a los manes de don Miguel de Unamuno que me perdonen: pienso que Sancho se va quijanizando, no quijotizando.

\section{Sobre La PLURIVOCALIDAD DE LA NOVELA}

Con gran acierto destacó Bajtín la plurivocalidad como carácter fundamental del Quijote. ${ }^{18}$. Si se admite lo que se ha procurado de-

${ }^{16}$ Sobre estos aspectos véase mi artículo "Sancho Panza y la cultura escrita", de próxima publicación en Studies in honor of Bruce W، Wardropper.

17 Véase en especial el cap. 12 de la Segunda parte.

18 Sobre estas tesis de Bajtín véase el agudo comentario de Fernando LÁZARo CARRETER, "La prosa del Quijote", en Lecciones cervantinas, Caja de Ahorros de Zaragoza, Aragón y Rioja, Zaragoza, 1985, pp. 113-129. 
mostrar más arriba, convendrá reconocer que esta plurivocalidad se manifiesta en la novela de manera más compleja de la que observó el propio crítico ruso. Quienes dialogan en las páginas del libro no son únicamente Don Quijote y Sancho, sino Don Quijote, Alonso Quijano y Sancho - y sin duda, más exactamente, Don Quijote, Alonso Quijano, Sancho el rústico y Sancho el culto. El carácter heterofónico de la novela es mucho más acentuado de lo que se ha sospechado. Se entiende que al tratar de heterofonía y dialogismo no me refiero a las solas formas del hablar, sino también y sobre todo a los contenidos que acarrean éstas.

Acertadamente observó André Malraux que detrás de la jerga de Nucingen no se percibe ninguna voz. Lo mismo se podrá decir del sayagués de tantos pastores teatrales. Pero no del hablar de Sancho que siempre refleja una visión del mundo, que siempre expresa una cultura. Un ejemplo entre ciento que se podrían aducir: a la astronomía de Alonso Quijano, que es astronomía del libro (II, 29), opone Sancho su astronomía, que es astronomía de pastor (II, 41). Ya se ve cómo, echando por este camino, nos encontramos otra vez con el concepto de personaje, este incontournable personaje, cuya muerte se apresuraron a proclamar, hace unos treinta años, unos petulantes jóvenes.

Sobre todo tenemos interés en examinar el desdoblamiento del héroe manchego y sus consecuencias, lo cual proyecta nueva luz sobre unos episodios cuya interpretación ha hecho correr mucha tinta. Pienso en especial en las pláticas que sostienen Don Quijote, el Caballero del Verde Gabán y su hijo don Lorenzo. Los capítulos 16, 17 y 18 de la Segunda parte de la novela presentan unos vaivenes incesantes en los que el interlocutor de don Diego de Miranda y de don Lorenzo cambia constantemente. Quien alaba la caballería andante, quien se dirige en tono áspero y agresivo a Diego de Miranda - "Váyase vuesa merced, señor hidalgo, a entender con su perdigón manso y con su hurón atrevido, y deje a cada uno hacer su oficio [... ] si vuesa merced no quiere ser oyente desta que a su parecer ha de ser tragedia, pique la tordilla y póngase en salvo" - , quien se glorifica de su triunfo sobre el león, quien define la ciencia andantesca, quien aconseja a don Lorenzo que abrace la profesión de andante es Don Quijote. Quien discurre sobre las relaciones entre padres e hijos, quien elogia elocuentemente la poesía, quien recuerda unos versos de Garcilaso, quien admira el maravilloso silencio que reina en la morada manchega, quien habla sin ilusión de las justas poéticas es Alonso Quijano. El texto subraya este juego de luces y sombras al insistir re- 
petidamente sobre las opiniones fluctuantes de Diego de Miranda y su hijo acerca de la salud mental de su huésped, al distribuir en forma equitativa los calificativos de "mentecato", "loco", "cuerdo" y "discreto", al crear en fin la famosa fórmula sobre el "entreverado loco, lleno de lúcidos intervalos"19.

Consecuencia de esta perspectiva es que Alonso Quijano viene a ser personaje clave en la novela. No sólo alimenta su presencia la fecunda dualidad del andante y del hidalgo, del alucinado y del discreto, sino que abre camino al diálogo entre amo y criado que, de no terciar Alonso Quijano en el libro, pronto quedaría sofocado. Tan poco entiende Sancho de caballerías, tan lejos anda del universo quimérico de don Quijote que sus conversaciones con el andante pronto se reducirían a unas proposiciones contrapuestas, anquilosadas en oposiciones elementales parecidas a las que manifiesta la primera plática entre caballero y escudero:

[...] bien podría ser que antes de seis días ganase yo tal reino, que tuviese otros a él adherentes, que viniesen de molde para coronarte por rey de uno dellos $[\ldots]$

-De esa manera - respondió Sancho Panza-, si yo fuese rey por algún milagro de los que vuestra merced dice, por lo menos Juana Gutiérrez, mi oíslo, vendría a ser reina $[\ldots](\mathrm{I}, 7)$.

Pronto pararía en seco el diálogo o desembocaría en yuxtaposición de monólogos. Don Quijote "necesitaba a Sancho - escribe Unamuno-, necesitábalo para hablar"'20. Sancho, en cuanto a él, necesitaba para hablar a Alonso Quijano, porque con Alonso Quijano, y no con Don Quijote, podía charlar, podía preguntar, podía cambiar ideas - podía mantener auténtico diálogo. La novela, por lo que es de ella, necesitaba de Alonso Quijano para que la plurivocalidad desarrollara plenamente sus virtualidades. Se suele considerar que el libro cervantino viene a ser novela en el momento en que entra en él Sancho Panza. Pero la intervención de Alonso Quijano es innovación tan decisiva como la aparición del

${ }^{19}$ Acaso convenga revisar a la luz de la misma observación las apreciaciones del manchego sobre las imágenes que descubre en cierto pradillo verde. San Jorge calificado como "uno de los mejores andantes", San Martín como uno de "los aventureros cristianos", Santiago como "uno de los más valientes santos y caballeros", San Pablo como "caballero andante por la vida" (II, 58), ¿serán informaciones sobre el pensamiento religioso de Cervantes, ¿o simples reflejos de la manía del andante?

${ }^{20}$ Vida de don Quijote y Sancho, cap. 7. 
escudero. Tanto como la de Sancho, la creación de Alonso Quijano funda el libro como novela.

\section{La paradoja de Don Quijote}

Es lugar común observar que el protagonista de la Segunda parte es distinto del que actúa en la Primera parte. Únicamente el desdoblamiento del personaje en Don Quijote y Alonso Quijano puede justificar esta alteración. Habiendo corrido sólo unos pocos meses desde la primera salida del caballero, no vale la hipótesis de que hubiera evolucionado o madurado el héroe (y la hipótesis raya en lo absurdo si recordamos que se trata de un cincuentón). Don Quijote no refiere la historia de una vida; Don Quijote no es ninguna educación sentimental, ningún itinerario intelectual. Ésta es la paradoja de la novela. Nos van diciendo (y dicen bien) que Don Quijote es la primera novela europea. Los grandes novelistas europeos del siglo XIX son frecuentemente convencidos y declarados admiradores del Quijote. Pero entre las novelas decimonónicas y Don Quijote existe una diferencia básica, que no parece haberse advertido. Los personajes de la novela decimonónica siempre tienen niñez, siempre tienen juventud, y niñez y juventud que determinan su trayectoria vital, llámense Lucien de Rubempré, Julien Sorel, David Copperfield o Gabriel Araceli, Emma Bovary ("Don Quijote con faldas"', decía Ortega) o Ana Ozores. Todos tienen historia. Y Alonso Quijano, no. Alonso Quijano es una cultura, no una historia.

Maxime Chevalier Université de Bordeaux III 